\title{
Micro-analytical GO/HRP bioreactor for glucose determination and bioprocess monitoring
}

\author{
V. Vojinović, C.R. Calado, A.I. Silva, M. Mateus, \\ J.M.S. Cabral, L.P. Fonseca* \\ Centro de Engenharia Biológica e Química, Instituto Superior Técnico, \\ Av. Rovisco Pais, 1049-001 Lisboa, Portugal
}

Received 21 May 2004; received in revised form 6 August 2004; accepted 11 August 2004

Available online 22 September 2004

\begin{abstract}
A bi-enzymatic micro-analytical bioreactor integrated in a FIA system for glucose measurements is described. Its robustness and small dimensions (working volume of about $70 \mu \mathrm{l}$ containing approximately $1.2 \mathrm{mg} \mathrm{GO}$ and $0.26 \mathrm{mg} \mathrm{HRP}$ ) make it easy to operate. The column is based on immobilisation of glucose oxidase (GO) and horseradish peroxidase (HRP) on alkylamine controlled pore glass (CPG) beads. The column has excellent shelf life (no significant loss of activity after 1 year if kept at $4{ }^{\circ} \mathrm{C}$ ), and a very high operational stability that was demonstrated through extensive usage for glucose determinations over 1 year period during which the column retained almost all of its activity. More importantly, this operational stability allows glucose monitoring in the culture media without a decay of signal over the experiment time and consequently no signal correction or re-calibration is needed. This high operational stability was also confirmed by continuous glucose conversion with $30 \%$ activity loss after converting quantity of glucose equivalent to 21600 FIA injections of $20 \mu 1$ with $1.7 \mathrm{mM}$ glucose. Such good performance is a result of an optimised immobilisation method and moreover of the implementation of in situ enzyme stabilisation strategy which consisted on promoting the instantaneous $\mathrm{H}_{2} \mathrm{O}_{2}$ consumption produced by the GO. This strategy has the additional advantage of allowing concomitant assay of the $\mathrm{H}_{2} \mathrm{O}_{2}$ based on the HAP catalysed co-oxidation of phenol-4-sulphonic acid (PSA) in the presence of 4-aminoantipyrine (4-AAP).

The glucose measurements are reproducible with high precision against the standard HPLC method. Linear range and sensitivity depend on sample injection volume; the upper limit is about $1.1 \mathrm{~g} / \mathrm{l}$. Lower detection limit is $10 \mathrm{mg} / \mathrm{l}$. The column performance has been validated for E. coli and $S$. cerevisiae fermentation monitoring, and glucose measurements in an animal cell culture (rat Langerhans islets).

(C) 2004 Elsevier B.V. All rights reserved.
\end{abstract}

Keywords: Biosensor; Glucose; Monitoring; Bi-enzymatic column; Horseradish peroxidase; Glucose oxidase

\section{Introduction}

Numerous reports and patent applications related to development of enzyme-based biosensors and analytical bioreactors have been published in recent years. Because of their intrinsic high selectivity and sensibility there has been a growing interest in biosensor development for bioprocess monitoring. So far in most of the processes in

\footnotetext{
* Corresponding author. Tel.: +35121841 9065; fax: +351 218419062.

E-mail address: Ifonseca@ alfa.ist.utl.pt (L.P. Fonseca). URL: http://www.dequim.ist.utl.pt/cebq/berg/index.html (L.P. Fonseca).
}

biotechnology off-line methods have been used for gathering information about concentrations of the analytes of interest. Most common off-line analytical assay methodologies are chromatography, colorimetric and enzymatic methods. Information gathered by off-line methods is analysed and used for development of mathematical models used to predict the parameters of the future processes. In situ measurements are limited to few parameters such as $\mathrm{pH}, \mathrm{pO}_{2}$, and temperature. Development of on-line (or quasi on-line) analytical methods is in most cases related to flow injection analysis (FIA) with amperometric, potentiometric, fluorescence and chemiluminescence detection, UV/VIS photometry, enzymatic assays 
and immunoassays but none of the proposed has been fully accepted and applied for on-line monitoring yet (Schügerl, 2001; Scheper et al., 1999; Schügerl et al., 1996).

Glucose is one of the most important analytes in bioprocess monitoring, and biosensors based on amperometric, photometric, optical, colorimetric, piesolectric and calorimetric measurement principles for glucose assay have been described (Schügerl, 2001; Schügerl et al., 1996).

A method for fast and reliable glucose on-line measurement would be very useful in monitoring and control of glucose-based bioprocesses and eventually for process automation. Process monitoring and control have a positive effect on process economisation (Scheper et al., 1999).

The potential applications of enzymes in analytical methods such as biosensors and analytical bioreactors are enormous, given that some of the fundamental problems hampering their development are successfully addressed. One of the problems is the enzyme instability, (i.e. storage or shelf life and operational stability), and it has remained one of the major hindrances to the commercialisation of these devices. Storage stability, or shelf life, refers to retention of activity of the biosensors when not in use and are stored under specific atmosphere, humidity, temperature, etc. The operational stability is retention of the activity when the biosensor is in use and is defined as measurement-tomeasurement signal decay expressed in percents of the initial activity of a single sensor over a period of time under continuous or intermittent monitoring.

Many of the enzymatic sensors developed to date, especially those intended for continuous monitoring purposes, have failed to exhibit a long-term, in-use stability, due to insufficient stability trials during their development.

Different solutions have been proposed to address the enzyme instability issue. These, among others, include: (1) the use of stabilising additives; (2) the immobilisation of the enzyme onto solid supports; (3) the manipulation of the environmental conditions (medium engineering); (4) enzyme screening or engineering with enhanced intrinsic stability; (5) the in situ removal of deactivators and inhibitors.

One of the major chemical degradations pathways of both native and denatured proteins is the oxidation of some amino acid residues, especially those containing a sulphur atom (Met, Cys) or an aromatic ring (His, Tyr, Trp, Phe), (Li et al., 1995). Those oxidative modifications are particularly relevant to the stability of biosensors based on oxidoreductase enzymes, such as oxidases and peroxidases, due to the presence of different reactive oxygen species in their catalytic cycle. This oxidation rate can, however, be accelerated by the presence of oxidants like hydrogen peroxide (Lasch et al., 2001), that is, usually only present as a contaminant, but that in the case of oxidases and peroxidases is a reaction product or substrate, respectively. On the other hand, oxidase enzymes are known to be inhibited and inactivated by $\mathrm{H}_{2} \mathrm{O}_{2}$, their reaction end-product (Bao et al., 2003).

Recently, mini packed-bed bioreactors containing horseradish peroxidase (HRP) and Hansenula polymorpha alcohol oxidase (AO) immobilized on alkylamine controlled pore glass beads (CPG) were assembled for monitoring and quantification of hydrogen peroxide and ethanol, respectively, using a flow injection analysis (FIA) system (Azevedo et al., 2004b, 2004c). The deactivation of alcohol oxidase micro-reactors $(31 \mu \mathrm{l})$ of $80 \%$ after $4 \mathrm{~h}$ during continuous oxidation of ethanol at $32{ }^{\circ} \mathrm{C}$ in phosphate buffer was attributed to inactivation by $\mathrm{H}_{2} \mathrm{O}_{2}$ rather than thermal deactivation (Azevedo et al., 2004a). Accordingly, an in situ stabilization strategy was devised that consisted in promoting the instantaneous consumption of hydrogen peroxide by HRP in the presence of reducing substrates, phenol-4-sulfonic acid (PSA) and 4-aminoantipyrine (4-AAP). Concomitantly, this strategy allows the assay of hydrogen peroxide, based on the PSA/4-AAP co-oxidation catalysed by HRP, as the product of the reaction is a quinone-imine dye that can be quantified spectrophotometrically. This strategy was also successfully applied to HRP immobilised onto same support that also led to high operational stability (Vojinović et al., 2004).

In this paper a FIA integrated sensor based on a bienzymatic analytical column containing immobilised glucose oxidase (GO) and horseradish peroxidase (HRP) is described. When the analyte (glucose) comes in contact with immobilised GO, it is oxidised to gluconic acid and an equivalent of hydrogen peroxide is produced. Peroxidase reduces the hydrogen peroxide oxidising the PSA/4-AAP system dissolved in the carrier thus producing quinone-imine dye. Colorimetric reaction is based on a modified Trinder method (Trinder, 1969; Trinder and Webster, 1984) that instead of phenol uses PSA, which is more soluble and less hazardous to human health and environment. This modification makes the system more suitable for prolonged on-line analysis (Vojinović et al., 2004). The bi-enzymatic GO/HRP column is placed in a convenient flow injection system that makes possible the sampling automation and high sampling frequency. Furthermore, the carrier solution is used in those experiments as a new medium engineering strategy of the biocatalysts' microenvironment in order to reach maximal activity and stability. It is particularly designed for the oxidase enzymes that are inhibited and inactivated by hydrogen peroxide, one of their reaction end-product (Bao et al., 2003). This new in situ stabilization strategy has been successfully applied for glucose measurements in three model bioprocesses: Escherichia coli and Saccharomyces cerevisiae fermentations and analysis of animal cell culture medium showing that the coupled GO/HRP bioreactor could be used as a valuable tool in process monitoring, control, and eventual bioprocess automation.

\section{Materials and methods}

Alkylamine CPG beads were obtained from CPG (USA). GO and HRP enzymes were purchased from Biozyme (UK). Gluteraldehyde, and 4-AAP were from Sigma-Aldrich (Germany), while PSA was from Fluka (Germany). D(+)glucose monohydrate, $\mathrm{NaCl}$, phosphate salts, $\mathrm{HCl}, \mathrm{H}_{2} \mathrm{SO}_{4}$ 
and $\mathrm{NaOH}$ used for preparation of sodium phosphate buffer and acid/base solution for fermentation $\mathrm{pH}$ control were from Merck (Germany). Yeast extract and yeast nitrogen base without aminoacids were from Difco (USA), bactotryptone from BD (USA), and peptone was from BDH (UK). Distilled and demineralised water was used in all the experiments.

\subsection{Column construction}

Enzymes were immobilised by glutaraldehyde cross linking: alkylamine CPG beads were activated by a reaction with $3 \%$ glutaraldehyde ( $1 \mathrm{~h}$, room temperature, agitated), washed with distilled water and submersed in a $6 \mathrm{mg} / \mathrm{l}$ enzyme solution, and left to react over night at room temperature with agitation, (Leirão et al., 2003). Beads with immobilised enzymes were washed and $14.6 \mathrm{mg}$ of beads with immobilised GO was mixed with same quantity of beads with immobilised HRP and the mixture was filled into a glass column of $3.2 \mathrm{~mm}$ diameter and about $8 \mathrm{~mm}$ active bi-enzymatic layer length. Activity of free and immobilised enzymes was measured by method described in Vojinović et al. (2004).

\section{2. $H P L C$}

For the off-line analysis an Aminex fermentation monitoring $150 \times 7.8$ chromatography column from Biorad (USA) with $0.5 \mathrm{mM} \mathrm{H}_{2} \mathrm{SO}_{4}$ (Merck, Germany) solution as the eluent at $50^{\circ} \mathrm{C}$ was used. A Merck-Hitachi (Germany) HPLC system was used: a L-6200 intelligent pump, a Merck L7490 refraction index detector; signal was registered and integrated with a D-2500 chromato-integrator (Merck-Hitachi), and sample injection was performed with a AS 2000A autosampler (Merck-Hitachi).

\subsection{FIA}

The same equipment used for HPLC analyses was used for FIA experiments, except that instead of chromatography column and the refraction index detector a bi-enzymatic GO/HRP analytical column and a UV/VIS detector (L-4000 UV, Merck-Hitachi, Germany) was used.

The carrier solution contained $25 \mathrm{mM}$ PSA, $0.4 \mathrm{mM} 4-$ AAP in $100 \mathrm{mM}$ phosphate buffer $\mathrm{pH}$ 7. In case of operational stability experiment with continuous glucose conversion by the column containing only the immobilized glucose oxidase, the carrier solution also contained $0.4 \mathrm{~g} / \mathrm{l} \mathrm{HRP.} \mathrm{Signal} \mathrm{was} \mathrm{de-}$ tected continuously at $490 \mathrm{~nm}$. Carrier solution was aerated at room temperature (approximately $25^{\circ} \mathrm{C}$ ) in order to maintain level of dissolved oxigen constant under given experimental conditions (Vojinović et al., 2004).

\subsection{Model bioprocesses for GO/HRP column validation}

The micro-analytical column validation has been performed for 3 different model bioprocesses: E. coli batch cultivation (two different media composition), S. cere- visiae batch cultivation, and a bioartifical pancreas device experiment.

\subsubsection{Microorganism and inoculum preparations}

E. coli pre-cultivations were performed in cotton-stopped shake flasks at $37^{\circ} \mathrm{C}$ and $250 \mathrm{rpm}$ in an orbital shaker (Agitorb $160 \mathrm{E}$, Aralab, Portugal), containing $10 \mathrm{~g} / \mathrm{l}$ yeast extract, $20 \mathrm{~g} / \mathrm{l}$ bactotryptone and $10 \mathrm{~g} / \mathrm{l}$ sodium chloride and $30 \mu \mathrm{g} / \mathrm{ml}$ kanamycine. S. cerevisiae pre-cultivation conditions were: $6.7 \mathrm{~g} / \mathrm{l}$ yeast nitrogen base without aminoacids and $20 \mathrm{~g} / \mathrm{l} \mathrm{glu}-$ cose at $30^{\circ} \mathrm{C}$ agitated also by an orbital shaker at $200 \mathrm{rpm}$.

\subsubsection{E. coli cultivation}

The pre-cultures were used for inoculation of the culture at $5 \%(\mathrm{v} / \mathrm{v})$. The cultivations were performed in a 51 bioreactor (Biostat MD, B. Braun, Germany) containing 31 working volumes. Bioreactor $\mathrm{pH}$ was maintained at $\mathrm{pH} 7.0$ by automatic control through $4 \mathrm{M} \mathrm{NaOH}$ or $2 \mathrm{M} \mathrm{H}_{2} \mathrm{SO}_{4}$ addition, and at $37^{\circ} \mathrm{C}$ with a minimum of dissolved oxygen tension of $30 \%\left(\mathrm{pO}_{2}\right)$ air saturation by automatic adjustment of the agitation rate as a constant air flow rate of $3.0 \mathrm{l} / \mathrm{min}(1.0 \mathrm{vvm})$ was applied. The cultivation medium contained $24 \mathrm{~g} / \mathrm{l}$ yeast extract, $10 \mathrm{~g} / \mathrm{l}$ bactotryptone, $5 \mathrm{~g} / \mathrm{l}$ sodium chloride and $20 \mathrm{~g} / \mathrm{l}$ $\mathrm{D}(+)$-glucose anhydrous. The medium for the second E. coli experiment differed from the former in glucose and yeast extract concentrations that were 10 and $5 \mathrm{~g} / \mathrm{l}$, respectively.

\subsubsection{S. cerevisiae cultivation}

Cultivation medium contained $20 \mathrm{~g} / \mathrm{l}$ glucose, $20 \mathrm{~g} / \mathrm{l}$ yeast extract and $20 \mathrm{~g} / \mathrm{l}$ peptone. Cultivation was performed in a 51 bioreactor (Biostat MD, B. Braun, Germany) at $30^{\circ} \mathrm{C}$, $\mathrm{pH}$ was controlled to 7.0 by addition of $1 \mathrm{M} \mathrm{NaOH}$ or $1 \mathrm{M}$ $\mathrm{HCl}$ solutions, and $\mathrm{pO}_{2}$ was maintained on $30 \%$ of saturation by means of controlling agitation rate. Aeration was held constant at $3.01 / \mathrm{min}$. Bioreactor working volume was 31 .

Samples were filtered with Millex GS $0.22 \mu \mathrm{m}$ filters from Millipore (USA). One part of each sample was diluted and injected immediately into the FIA and the other part was frozen and kept for the later HPLC analysis.

\subsection{Bioartificial pancreas experiment}

The experiment with bioartificial pancreas device was performed with a hollow fibre reactor with rat Langerhans islets displaced in the anular space of the reactor and the nutritive medium recirculating through the inner tube lumen. Nutritive medium was CMRL-1066 medium for animal cell cultures (Gibco, USA), with the addition of $10 \%$ FCS (fetal calf serum), $2 \mathrm{mM}$ L-glutamine, $100 \mathrm{U} / \mathrm{ml}$ penicillin, $100 \mu \mathrm{g} / \mathrm{ml}$ streptomycin, $0.25 \mu \mathrm{g} / \mathrm{ml}$ fungizone (all from Gibco, USA),

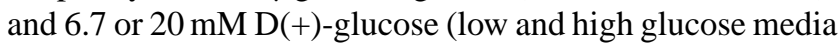
concentrations) from Merck (Germany). The first part of the experiment was performed with high glucose medium (glucose challenge phase), and after about $9 \mathrm{~h}$ the medium was removed and replaced with the low glucose medium (basal phase) that lasted about $18 \mathrm{~h}$. The analysed samples were 
taken from 10 different experiments at the end of the glucose challenge phase and after the basal phase. Diluted samples were injected into FIA system and compared later with offline HPLC analysis.

\section{Results and discussion}

\subsection{Storage or shelf life of the bi-enzymatic GO/HRP columns}

The storage or shelf life of this micro-analytical bienzymatic GO/HRP column was confirmed for a period of over a year. The column was kept under $4{ }^{\circ} \mathrm{C}$, and after 1 year period it was still operational and easily calibrated. This high stability is due to the optimisation of the experimental conditions and immobilisation method used. High shelf stability has already been observed for the HRP and alcohol oxidase (AO) immobilised individually also into CPG beads using the same immobilisation method (Azevedo et al., 2004b, 2004c). It was also observed that loss of activity of the HRP columns did not occur during about 2 months of storage at $25^{\circ} \mathrm{C}$ or when in continuous contact with the carrier solution containing $25 \mathrm{mM}$ PSA and $0.4 \mathrm{mM}$ 4-AAP in $100 \mathrm{mM}$ phosphate buffer pH 7.0 also at $25^{\circ} \mathrm{C}$ (Azevedo et al., 2004c). Long shelf life of a controlled pore glass immobilized glucose oxidase has been previously reported. In an experiment with a column of $2.5 \mathrm{~mm}$ diameter and $2.5 \mathrm{~cm}$ length over 10 months period a very small loss in activity was reported (Masoom and Townshend, 1984).

\subsection{Operational stability of the bi-enzymatic GO/HRP column}

For the period of over a year, another bi-enzymatic GO/HRP column prepared from the same mixture of GO and HRP beads was extensively used (all the experiments were performed with the same column which corresponds to thousands of injections for glucose analysis, at least in triplicate) for glucose analyses of the samples from E. coli and $S$. cerevisiae complex fermentation media, animal cell cultures, and standards for FIA calibration and validation experiments. Over this period the bi-enzymatic GO/HRP column preserved almost all the activity (activity loss less than $10 \%$ ) and it could be successfully used for intermittent glucose measurements in different complex culture media and it was easily recalibrated.

A different immobilization system based on Sepharose 6B immobilized glucose oxidase packed bed micro-columns (about $100 \mu \mathrm{l}$ working volume) employed in a reagent based flow injection glucose measurement method by (Nandakumar et al., 1999) resulted in columns with sufficient operational stability for over 600 measurements. Detection range for this system was much lower than for the method described in this paper (about 10 times lower) so the deactivating effects of hydrogen peroxide that is produced by the reaction catal- ysed by glucose oxidase are lower. Injections of lower glucose concentration samples allow for higher measured operational stability. Pacakova et al. (Pacáková et al., 1992) reported a $200 \mu \mathrm{l}$ packed bead column reactor with glucose oxidase immobilized on HEMA Bio 1000 sorbents (ethylene glycol dimethacrylate and hydroxy-methacrylate copolymer hydrofilic gels) with $16.3 \mathrm{mg}$ of protein per gram of the sorbent. Glucose is measured by amperometric detection of hydrogen peroxide produced in the column. Reported linear range was $0.01-10 \mathrm{mM}$ of glucose. After 3 months this column is reported to retain $25 \%$ of its initial activity. After about 100 injections of $25 \mu \mathrm{l}$ with $5.5 \mathrm{mM}$ glucose standards the signal decayed very rapidly.

Repeated injections of a standard glucose solution into the FIA system with the integrated bi-enzymatic GO/HRP column over $24 \mathrm{~h}$ gave reproducible signal with relative standard deviation of $1 \%$. Injections were performed every $10 \mathrm{~min}$ (total of 150 repetitions), injection volume was $10 \mu \mathrm{l}$ and concentration of glucose in the standard solution was $500 \mathrm{mg} / \mathrm{l}$ (2.5 mM) (Fig. 1).

This excellent operational stability of the micro-analytical GO/HRP columns was also shown by the continuous conversion of glucose dissolved in a carrier solution (Fig. 2). The carrier solution contained $25 \mathrm{mM}$ PSA, $0.4 \mathrm{mM}$ 4-AAP, in $100 \mathrm{mM}$ phosphate buffer at $\mathrm{pH} 7$ with $1.7 \mathrm{mM}$ glucose and it was continuously pumped through two different columns: one containing GO immobilised onto CPG beads, and the other containing a mixture of GO and HRP immobilised beads. The carrier solution that was fed through column containing only GO immobilised also contained $0.4 \mathrm{~g} / \mathrm{l} \mathrm{HRP}(100 \mathrm{U} / \mathrm{ml})$. After $12 \mathrm{~h}$ of the continuous glucose conversion at a flow rate of $0.6 \mathrm{ml} / \mathrm{min}$, the volume of glucose feed is equivalent to about 21,600 injections in the FIA system of $20 \mu \mathrm{l}$ of $1.7 \mathrm{mM}$ glucose, and the total activity loss is about $30 \%$ for both columns. Azevedo (Azevedo et al., 2004b) reported for a $9.4 \mu \mathrm{l} \mathrm{col-}$ umn containing alcohol oxidase immobilized on CPG, and with $2 \mathrm{U} / \mathrm{ml}$ HRP dissolved in a reaction mixture, with the same composition of the carrier solution used in this work, and for those experiments were observed about $75 \%$ retained activity after $12 \mathrm{~h}$ of continuous conversion of $6.5 \mathrm{mM}$ ethanol.

Prediction of the column half life (time after which column shows half of its initial activity) based on 1st order exponential fit of the experimental data expressed in number of $25 \mu \mathrm{l}$ injections of $1.7 \mathrm{mM}$ glucose solution was 33,400 . This number of equivalent injections is lower but comparable with the value reported in (Azevedo et al., 2004c) for HRP immobilized column that was 112,800 injections of $25 \mu \mathrm{l}$ of $0.21 \mathrm{mM}$ hydrogen peroxide.

The in situ enzyme stabilisation strategy implemented for the alcohol oxidase immobilised on CPG and reported by Azevedo et al. (2004b) presented virtually the same stabilisation effect for HRP dissolved in carrier solution passing through the AO column, HRP co-immobilised with $\mathrm{AO}$ on CPG beads and HRP beads mixed with $\mathrm{AO}$ beads and 


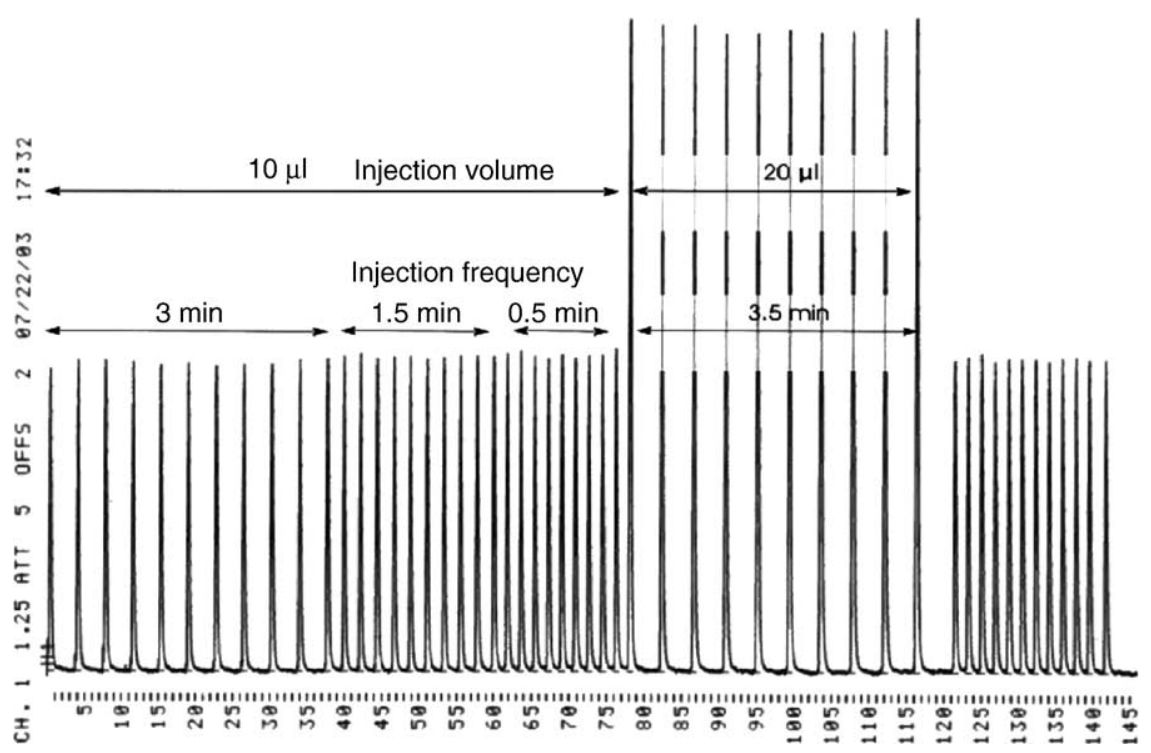

Fig. 1. Signal reproducibility: repeated injections of $10 \mu \mathrm{l}$ of $2.5 \mathrm{mM}$ glucose standard solution to the FIA system integrating a bi-enzymatic GO/HRP analytical column with different injection frequency and injection volumes.

in the last two cases, the beads were filled into bi-enzymatic columns.

\subsection{Calibration and throughput of the FIA system with a bi-enzymatic GO/HRP column}

FIA signal peak size and shape depend on carrier flow rate, injection volume and temperature. The bi-enzymatic GO/HRP column was thermostated in all the experiments at $25^{\circ} \mathrm{C}$. A typical calibration curve is presented in Fig. 3. Calibration of the FIA system for three different carrier flow rates $(0.3,0.6$ and $1.0 \mathrm{ml} / \mathrm{min})$ and three different injection volumes $(10,30$ and $60 \mu \mathrm{l})$ showed that there is no strong

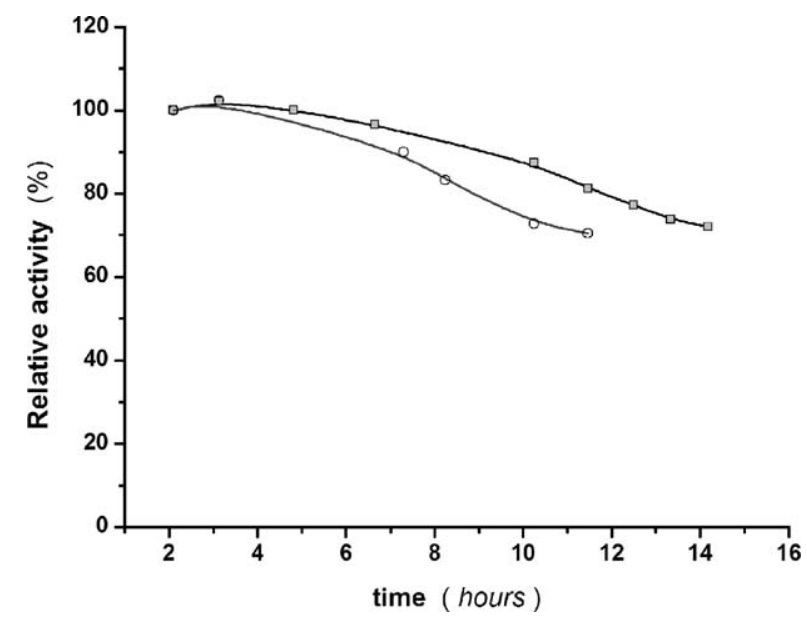

Fig. 2. Operational stability: successive absorbance readings of the effluent from two columns at flow rate of $0.6 \mathrm{ml} / \mathrm{min}$ : $(\square)$ bi-enzymatic GO/HRP column and $(\bigcirc)$ column containing only immobilised GO. Reagent solution contained $25 \mathrm{mM}$ PSA, $0.4 \mathrm{mM}$ 4-AAP and $1.7 \mathrm{mM}$ glucose in $100 \mathrm{mM}$ phosphate buffer $\mathrm{pH}$ 7. In case of GO column, the reagent solution also contained $0.4 \mathrm{~g} / \mathrm{l} \mathrm{HRP}$. dependence of linear range and lower detection limit on the flow rate while injection volume influences both linearity and lower detection limit. For $60 \mu \mathrm{l}$ injection volume standard solution of $10 \mathrm{mg} / \mathrm{l}$ of glucose produce a significant signal level (based on signal to noise ratio of 3). Linear range for the $10 \mu \mathrm{l}$ injections is about $0-1.1 \mathrm{~g} / \mathrm{l}$.

Increasing the injection volume from 10 to $60 \mu \mathrm{l}$ and reducing flow rate from 1 to $0.3 \mathrm{ml} / \mathrm{min}$ increases the sensitivity expressed as peak height (integrator units $-\mathrm{Iu}$ ) per unit of glucose concentration from 17 to $309 \mathrm{Iu} \mathrm{mg}^{-1} 1$.

Signal peak delay from the injection time was 30 and $50 \mathrm{~s}$ (for 1.0 and $0.3 \mathrm{ml} / \mathrm{min}$ flow rates, respectively), and samples were injected with frequency of $1.2 \mathrm{~min}$. Short analysis time

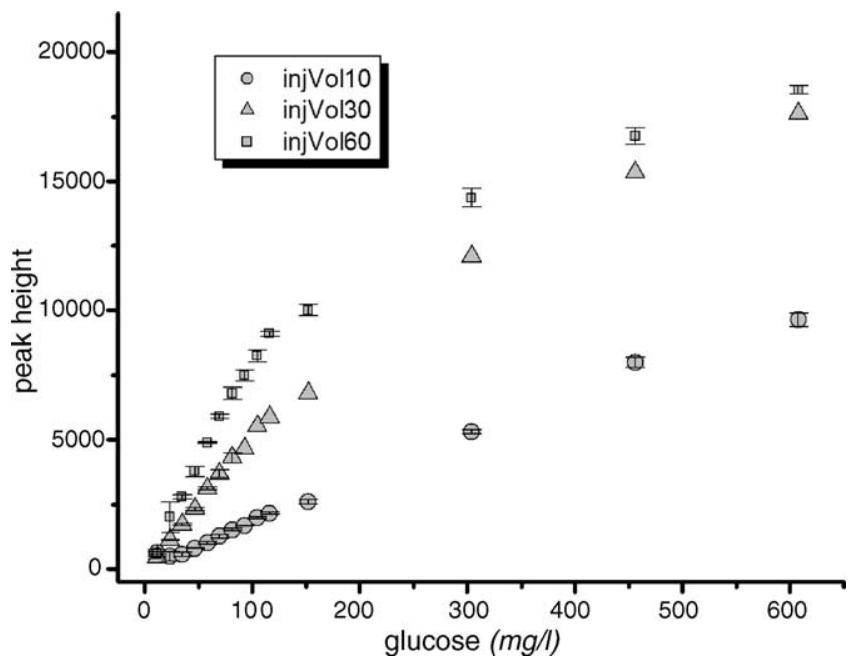

Fig. 3. Calibration of the bi-enzymatic GO/HRP analytical column in the FIA system. Carrier flow rate $1.0 \mathrm{ml} / \mathrm{min}$, injection volumes of (O) $10 \mu \mathrm{l}$,

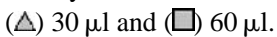


and high throughput (number of analyses per hour) of this system (around 50 injections per hour for $0.3 \mathrm{ml} / \mathrm{min}$ flow rate) is one of its advantages as it allows almost instantaneous information about the glucose concentration inside the reactor (quasi on-line analysis).

\subsection{Validation of the FIA system with a bi-enzymatic GO/HRP column}

The calibration curves were validated for measurements of glucose in two batch fermentations with E. coli, a batch fermentation with $S$. cerevisiae and in an experiment with bioartificial pancreas by comparing the results obtained with the standard HPLC method and the bi-enzymatic GO/HRP column.

Samples were aseptically taken from the bioreactor, filtered, diluted and injected into the flow injection system. The process took about $2 \mathrm{~min}$, and could be made more rapid by an automatic sampling system and automatic dilution within the FIA system. Signal stability over the fermentation time was confirmed by repeated injections of standard solution between the sample injections. No significant signal decay was observed (measured peak height differences for these repeated standard injections were within the $1 \%$ error) and no correction was needed over the fermentation time. The results of the measurements of the glucose concentrations by the HPLC and bi-enzyamtic GO/HRP column and biomass during the $E$. coli cultivation are presented in Fig. 4. Relative error between the FIA and HPLC measurements were lower than $3 \%$ for all the samples with more than $2 \mathrm{~g} / \mathrm{l}$ glucose. A comparison of the results by the two analytical methods for the three fermentation experiments is given in Fig. 5.

Results of the glucose measurements in the bioartificial pancreas experiment with the bi-enzymatic GO/HRP column, and comparison with HPLC measurements are shown in Fig. 6. Samples were diluted and injected into the FIA

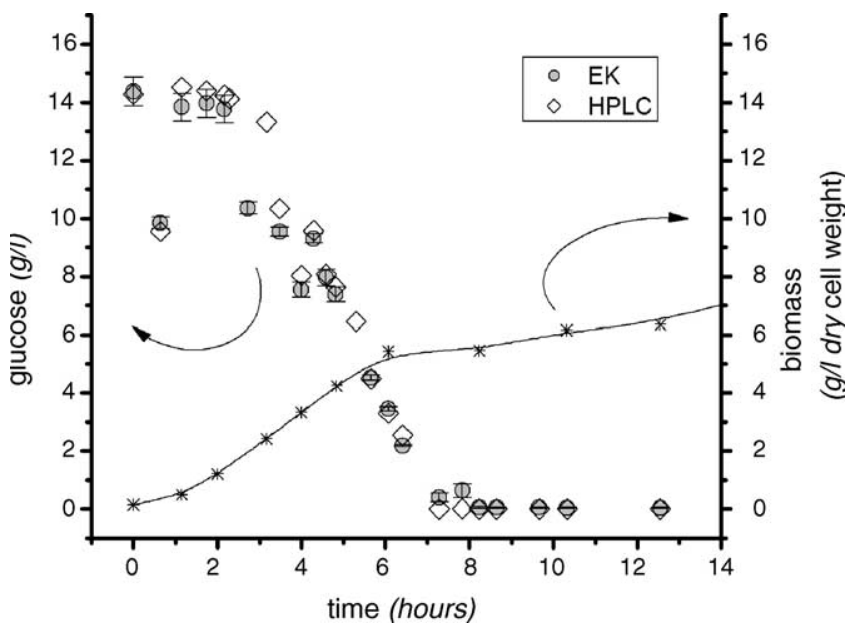

Fig. 4. Monitoring of glucose by HPLC $(\diamond)$ and bi-enzymatic GO/HRP column $(\mathrm{O})$ and biomass as gram of dry cell weight per litre of fermentation broth of $E$. coli cell growth in 31 batch bioreactor (*).

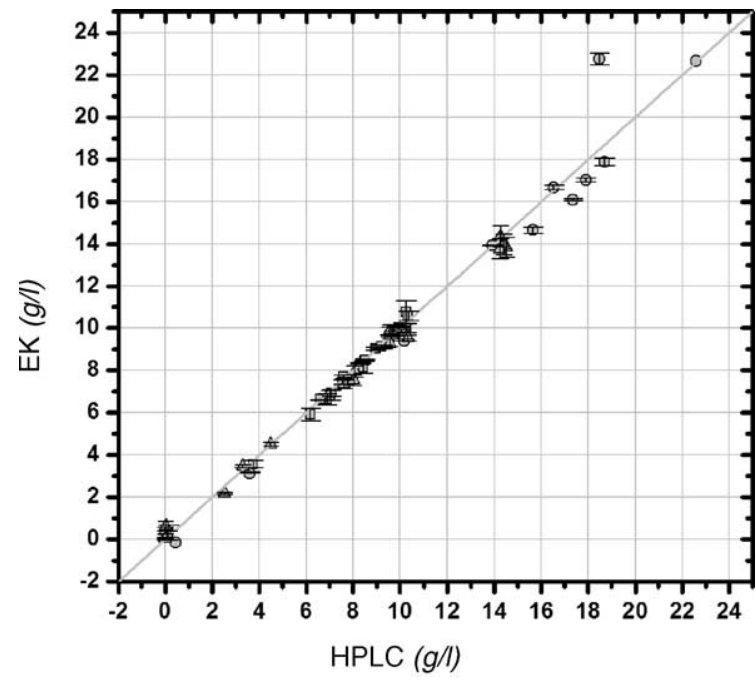

Fig. 5. Bi-enzymatic GO/HRP column (EK) vs. HPLC glucose measurements. (O) S. cerevisiae cultivation, $(\triangle) E$. coli cultivation with $24 \mathrm{~g} / 1$ yeast extract and $20 \mathrm{~g} / 1$ glucose medium, $(\square)$ E. coli cultivation with $5 \mathrm{~g} / 1$ yeast extract and $10 \mathrm{~g} / 1$ glucose medium. Correlation: $[\mathrm{Gluc}]_{\mathrm{EK}}=0.10( \pm 0.07)+$ $0.971( \pm 0.008) \times[\text { Gluc }]_{\mathrm{HPLC}}, R^{2}=0.997$, number of samples: $N=59$.

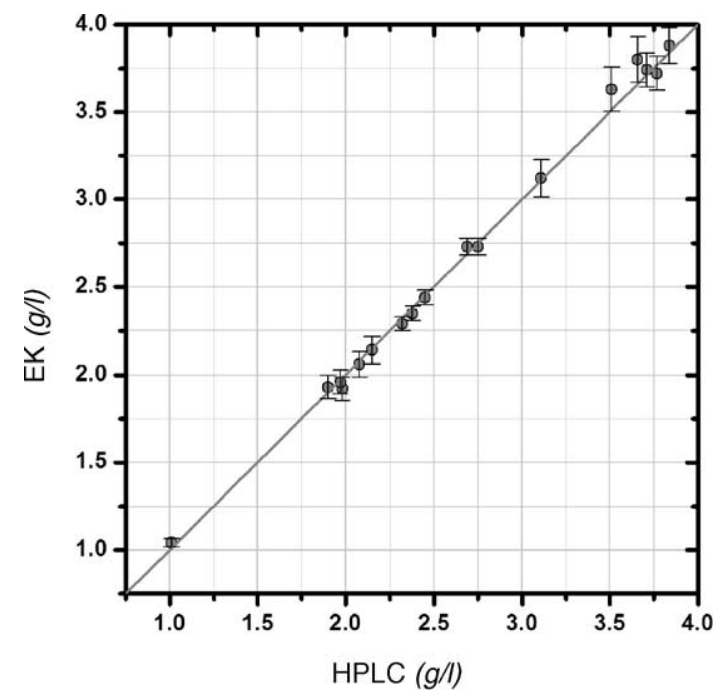

Fig. 6. Bi-enzymatic GO/HRP column (EK) vs. HPLC glucose measurements in animal cell culture media. Correlation: [Gluc $]_{\mathrm{EK}}=0.21( \pm 0.05)+$ $0.93( \pm 0.02) \times[\text { Gluc }]_{\text {HPLC }}, R^{2}=0.996$, number of samples: $N=17$.

system. A portion of each sample was frozen and kept for the off-line HPLC analysis. Relative error between the two methods was below $5 \%$ for all the samples.

\section{Conclusion}

It is shown that the described bi-enzymatic GO/HRP column can be successfully used for rapid glucose concentration measurements over prolonged periods of time. It has a very good reproducibility, good linear range and sensitivity, and there is no interference noted in the animal cell culture medium measurements. The column is very robust and easy 
to operate. Also high number of analyses per hour is possible with the described system.

The storage or shelf life of these bi-enzymatic GO/HRP columns was for at least 12 months at $4{ }^{\circ} \mathrm{C}$, which would allow rational production, inventory, shipping and customer test schedules. Furthermore, the operational stability, quoted as one of the most important parameters of a successful sensor, was also shown to be very high due to reusability capacity of the same column with different cultivation media and after numerous calibrations that corresponded to thousands of injections of glucose standards and real samples.

In conclusion this bi-enzymatic GO/HRP column can be seen as a potential commercially viable enzyme sensor for glucose. Furthermore, the immobilisation method and in situ enzyme stabilisation strategy has been easily implemented to detection and monitoring of other analytes (e.g. alcohol, galactose, lactose, lactate, maltose, etc.) combining HRP and $\mathrm{H}_{2} \mathrm{O}_{2}$ producing oxidases.

A drawback of the described glucose measuring system is that it requires external equipment (pumps, valves, spectrophotometer), but combining several similar oxidase/HRP columns for parallel detection of various analytes in an automated FIA will reduce the overall equipment cost per assay and also allow for the sample micro-manipulations such as automatic dilution and eventually complex calibration techniques.

The future work on these bi-enzymatic GO/HRP columns will be focused on solving of the problem of the interference that some compounds existing in the complex nutrient media especially when present in high concentrations might exhibit towards the glucose enzyme assay method. A way to overcome this problem is by performing high dilution and/or complex calibrations (calibration with standards containing both glucose and the compound that produce the interference).

The automation of the measurement together with automatic sampling and sample dilution in a FIA set-up is feasible. Future work will also comprise full automation of the measurements and construction of a device for on-line monitoring of glucose concentration in bioprocesses.

\section{Acknowledgements}

V. Vojinović gratefully acknowledges the PhD fellowship (SFRH/BD/5495/2001) from the program PRAXIS XXI, Ministério da Ciência e Tecnologia, Portugal.

\section{References}

Azevedo, A.M., Cabral, J.M.S., Prazeres, D.M.F., Gibson, T.D., Fonseca, L.P., 2004a. Thermal and operational stabilities of Hansenula polymorpha alcohol oxidase. J. Mol. Catal. B: Enzym. 27, $37-45$.

Azevedo, A.M., Cabral, J.M.S., Gibson, T.D., Fonseca, L.P., 2004b. Operation and performance of analytical packed-bed reactors with an immobilised alcohol oxidase. J. Mol. Catal. B: Enzym. 28, 45-53.

Azevedo, A.M., Vojinović, V., Cabral, J.M.S., Gibson, T.D., Fonseca, L.P., 2004c. Operational stability of immobilised horseradish peroxidase in mini-packed bed bioreactors. J. Mol. Catal. B: Enzym. 28, 121-128.

Bao, J., Furumoto, K., Yoshimoto, M., Fukunaga, K., Nakao, K., 2003. Competitive inhibition by hydrogen peroxide produced in glucose oxidation catalyzed by glucose oxidase. Biochem. Eng. J. 13, 69-72.

Lasch, P., Petras, T., Ullrich, O., Bachmann, J., Naumann, D., Grune, T., 2001. Hydrogen peroxide-induced structural alterations of RNase A. J. Biol. Chem. 276, 9492-9502.

Leirão, P.R.S., Fonseca, L.J.P., Taipa, M.A., Cabral, J.M.S., Mateus, M., 2003. Horseradish peroxidase immobilized through its carboxylic groups onto a polyacrylonitrile membrane. comparison of enzyme performances with inorganic beaded supports. Appl. Biochem. Biotechnol. 110, 1-10.

Li, S., Schöneich, C., Borchardt, R.T., 1995. Chemical-instability of protein pharmaceuticals - mechanisms of oxidation and strategies for stabilization. Biotechnol. Bioeng. 48, 490-500.

Masoom, M., Townshend, A., 1984. Determination of glucose in blood by flow-injection analysis and an immobilized glucose-oxidase column. Anal. Chim. Acta 166, 111-118.

Nandakumar, M.P., Sapre, A., Lali, A., Mattiasson, B., 1999. Monitoring of low concentrations of glucose in fermentation broth. Appl. Microbiol. Biotechnol. 52, 502-507.

Pacáková, V., Štulík, K., Le, K., 1992. Hydroxyethylmethacrylate column reactors with immobilized glucose oxidase or alcohol oxidase. Liquid chromatographic determination of ethanol in serum. Anal. Chim. Acta 257, 38-73.

Scheper, T., Hitzmann, B., Stark, E., Ulber, R., Faurie, R., Sosnitza, P., Reardon, K.F., 1999. Bioanalytics: detailed insight into bioprocesses. Anal. Chim. Acta 400, 121-134.

Schügerl, K., Hitzmann, B., Jurgens, H., Kullick, T., Ulber, R., Weigal, B., 1996. Challenges in integrating biosensors and FIA for on-line monitoring and control. Trends Biotechnol. 14, 21-31.

Schügerl, K., 2001. Progress in monitoring, modeling and control of bioprocesses during the last 20 years. J. Biotechnol. 85, 149-173.

Trinder, P., 1969. Determination of glucose in blood using glucose with an alternative oxygen acceptor. Ann. Clin. Biochem. 6, 24-27.

Trinder, P., Webster, D., 1984. Determination of HDL-cholesterol using 2,4,6-tribromo-3-hydrpxybenzoic acid with a commercial CHOD-PAP reagent. Ann. Clin. Biochem. 21, 430-433.

Vojinović, V., Azevedo, A.M., Martins, V.C.B., Cabral, J.M.S., Gibson, T.D., Fonseca, L.P., 2004. Assay of $\mathrm{H}_{2} \mathrm{O}_{2}$ by HRP catalysed co-oxidation of phenol-4-sulphonic acid and 4-aminoantipyrine: characterisation and optimisation. J. Mol. Catal. B: Enzym. 28, 129-135. 